\title{
DESAIN KEMASAN KARUNG YANG OPTIMAL UNTUK PENGEMAS BAHAN CURAH
}

\author{
LUSI ZAFRIANA \\ Fakultas Teknik Industri Universitas Kartini (UNKAR) Surabaya \\ E-mail: lusizafriana@yahoo.com
}

\begin{abstract}
ABSTRAK
Banyak material dalam jumlah besar seperti semen, garam, dan berbagai produk konsumsi primer menggunakan pengemasan tas plastik dari polypropylene. Karena ukuran pengemasan sangat bergantung pada kerapian jenis material, maka diperlukan optimalisasi desain dari ukuran ukuran tas plastik berdasarkan jenis material (kerapatan jumlah besar) dan bobot kerapian produk. Aplikasi algoritma matematik sederhana, di mana ukuran volume karung akan dirubah menjadi bobot jumlah material, maka optimisasi dari panjang dan lebar karung akan sesuai dengan berat jenis material yang diisikan ke dalam pengemasan dapat ditentukan. Menggunakan metode trial error, nilai l (lebar) dan p (panjang) tas plastik, maka dapat diperkirakan tas plastic dapat menampung material seberat $m$ kilogram.
\end{abstract}

Kata Kunci: ukuran optimal, bobot isi, bobot curah

\begin{abstract}
Many bulk material like cement, salt, and other primer consumer goods product using of plastic bag package made from polypropylene. Because size of the packaging hardly depend on tidy material types, hence it's required an optimization design of size plastic bag that matching with material type (bulk density) and tidy product weight. Applied simple mathematics algorithm, where volume value sack will be converted to bulk material weight, hence optimization of length and wide sack matching with bulk density material filled in in packaging will be able to be determined. Using trial error method, value $\boldsymbol{l}$ (wide) and $\boldsymbol{p}$ (length) plastic bag, hence expected plastic bag will be able to load material as heavy $\boldsymbol{m}$ kilogram.
\end{abstract}

Key words: optimal size, bulk density, bulk material

\section{PENDAHULUAN}

Bahan-bahan curah di sekitar kita, seperti beras, garam hingga bahan-bahan seperti semen, dan lainlain biasa dikemas dalam wadah karung plastik. Karung plastik ini biasanya dibuat dari bahan

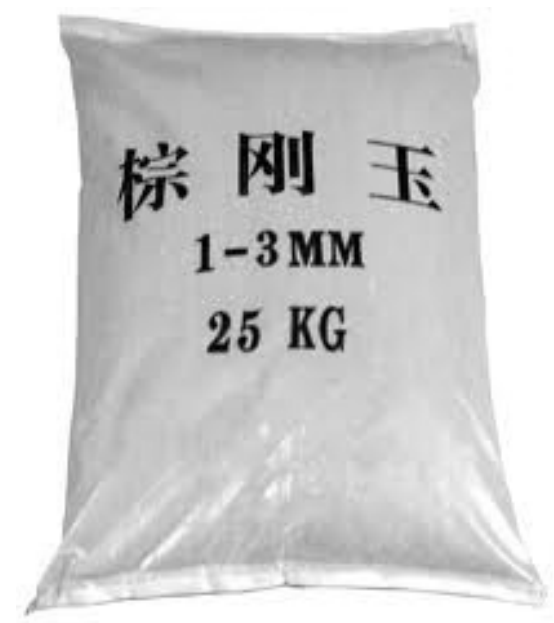

Gambar 1. Karung Woven polipropilen, yaitu sejenis polimer yang tersusun atas monomer-monomer propilen. Karung dari bahan ini bisa dibuat dalam bentuk karung film ataupun karung woven (anyaman).

Ukuran karung woven yang sesuai akan sangat tergantung pada jenis bahan curah yang akan diisikan ke dalamnya. Untuk berat yang sama (misalnya $25 \mathrm{~kg}$ ), bahan curah dengan bulk density $0,5 \mathrm{~g} / \mathrm{cc}$ misalnya akan memerlukan ukuran karung yang lebih besar dibandingkan untuk bahan curah dengan bulk density $0,8 \mathrm{~g} / \mathrm{cc}$. Pada umumnya yang terjadi di dunia praktek, komunikasi antara konsumen dan produsen terkait dimensi karung ini tidak begitu jelas, yaitu hanya berdasarkan pengalaman. Sebagai contoh ukuran karung untuk kemasan beras $15 \mathrm{~kg}$ ialah $42 \times 68 \mathrm{~cm}$. Untuk bahan lain di mana ukuran yang sesuai belum diketahui, pihak produsen biasanya akan mencoba-coba berbagai ukuran terlebih dahulu sebelum bisa menetapkan ukuran yang sesuai. Hal ini tentu saja tidak praktis.

Pada penelitian ini akan diungkap suatu cara untuk menghitung dimensi karung yang optimal 
disesuaikan dengan jenis bahan yang akan diisikan. Dalam hal ini bulk density dari bahan akan menjadi penentu dimensi tersebut. Dengan rumusan yang diperoleh maka penetapan ukuran karung untuk kemasan bahan curah tertentu, di mana selama ini belum diketahui ukuran karungnya, bisa dilakukan secara mudah dan cepat.

\section{METODE}

Dalam mendesain kemasan karung yang optimal, maka dibutuhkan rumus perhitungan dimensi karung. Yang menyebabkan penentuan dimensi karung menjadi sulit ialah karena karung hanya punya dua ukuran, yaitu lebar dan panjang saja. Tidak ada parameter tebal karung, sehingga volume karung tidak bisa dihitung dengan rumus volume biasa.

Misalkan seorang usahawan beras sedang mempertimbangkan untuk menggunakan woven bag sebagai pengemas komoditasnya. Dia berencana mengemas produk usahanya dalam kemasan $17 \mathrm{~kg}$. Jika diamati, pada awalnya, woven bag akan berbentuk seperti Gambar 2-a sebelum diisi dengan bahan. Profil akan berubah menjadi Gambar 2-b setelah diisikan bahan. Jika 1 adalah lebar karung dan $\mathrm{p}=$ panjang karung maka suatu woven bag yang termuati akan berkurang lebar dan tingginya sepanjang (x/2) kanan kiri atau atas bawah. Yang terjadi adalah suatu bentukan balok dengan panjang ( $\mathrm{p}-\mathrm{x}$ ), lebar (l-x) dan tebal $\mathrm{x}$.

Dengan mengabaikan volume di luar bentukan balok (di bawah/atas tekukan), maka volume karung
V bisa dihitung secara sederhana sbb:

$\mathrm{V}=$ tebal $\times$ panjang $\times$ lebar $=x(p-x)(l-x)$

Jika rasio lebar terhadap tebal karung setelah diisi bahan ialah $\mathrm{R}$ (jadi $\mathrm{R}=\mathrm{l} / \mathrm{x}$ ), maka volume karung $\mathrm{V}$ menjadi:

$$
\begin{aligned}
\mathrm{V} & =x(p-x)(l-x) \\
& =\frac{l}{R}\left(p-\frac{l}{R}\right)\left(l-\frac{l}{R}\right) \\
& =\frac{l^{2}(R-1)(R p-l)}{R_{3}}
\end{aligned}
$$

Didapatkan rumus volum karung:

$\mathrm{V}=\frac{l^{2}(R-1)(R p-l)}{R^{3}}$

Untuk bisa menghitung $\mathrm{V}$, maka nilai $\mathrm{R}$ perlu ditetapkan dengan cara memilih suatu nilai yang mengoptimalkan V. Hal ini bisa dilakukan dengan syarat $\mathrm{dV} / \mathrm{dR}=0$.

$$
\begin{gathered}
\mathrm{V}=\frac{l^{2}(R-1)(R p-l)}{R^{3}} \\
\mathrm{~V}=l^{2}\left(\frac{R^{2} p-R l-R p+l}{R^{3}}\right)=l^{2}\left(\frac{p}{R}-\frac{l}{R^{2}}-\frac{p}{R^{2}}+\frac{l}{\mathrm{R}^{3}}\right) \\
\frac{d V}{d R}=l^{2}\left(-\frac{p}{R^{2}}+\frac{2 l}{R^{3}}+\frac{2 p}{R^{3}}-\frac{3 l}{\mathrm{R}^{4}}\right)=0 \\
-\frac{p}{R^{2}}+\frac{2 l}{R^{3}}+\frac{2 p}{R^{3}}-\frac{3 l}{\mathrm{R}^{4}}=0
\end{gathered}
$$

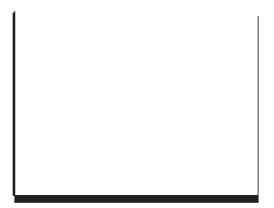

woven bag sebelum dimuati

(a)

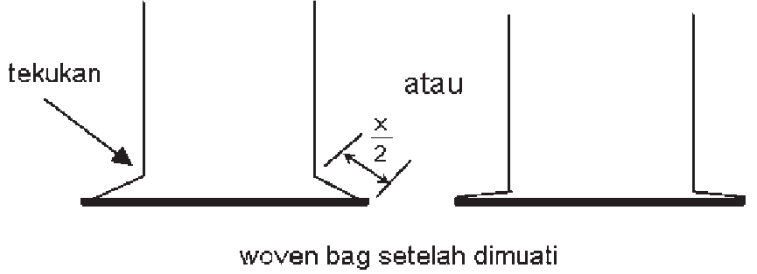

(b)

Gambar 2. Hipotesis Profil Karung Sebelum dan Sesudah Dimuati

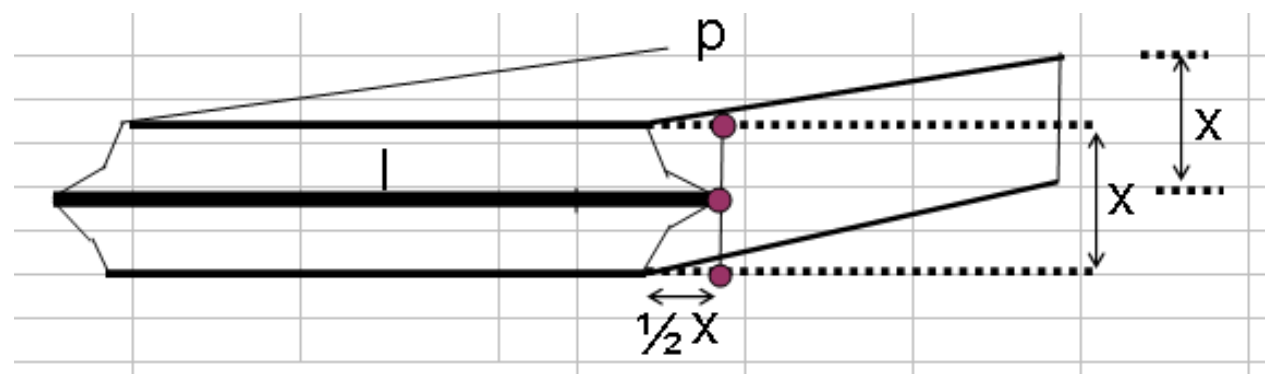

Gambar 3. Profil Karung Dalam Penampang Balok 


$$
\begin{gathered}
-p R^{2}+2 l R+2 p R-3 l=0 \\
p R^{2}-2 l R-2 p R+3 l=0
\end{gathered}
$$

$p R^{2}-2 R(l+p)+3 l=0$

Dengan mengenakan rumus ABC untuk mencari akar persamaan kuadrat maka diperoleh:

$$
\begin{gathered}
\mathrm{R}_{1,2}=\frac{2(l+p) \pm \sqrt{4(l+p)^{2}-12 l p}}{2 p} \\
\mathrm{R}_{1,2}=\frac{2(l+p) \pm \sqrt{4 l^{2}+4 l p+4 p^{2}}}{2 p} \\
\mathrm{R}_{1,2}=\frac{2(l+p) \pm 2 \sqrt{l^{2}-l p+p^{2}}}{2 p} \\
\mathrm{R}_{1,2}=\frac{(l+p) \pm \sqrt{l^{2}-l p+p^{2}}}{2 p}
\end{gathered}
$$

Sehingga:

$\mathrm{R}=\frac{(l+p)+\sqrt{l^{2}-l p+p^{2}}}{p}$

Persamaan (2) dan (4) adalah persamaanpersamaan yang akan digunakan untuk perhitungan dimensi (lebar dan panjang) karung yang optimal.

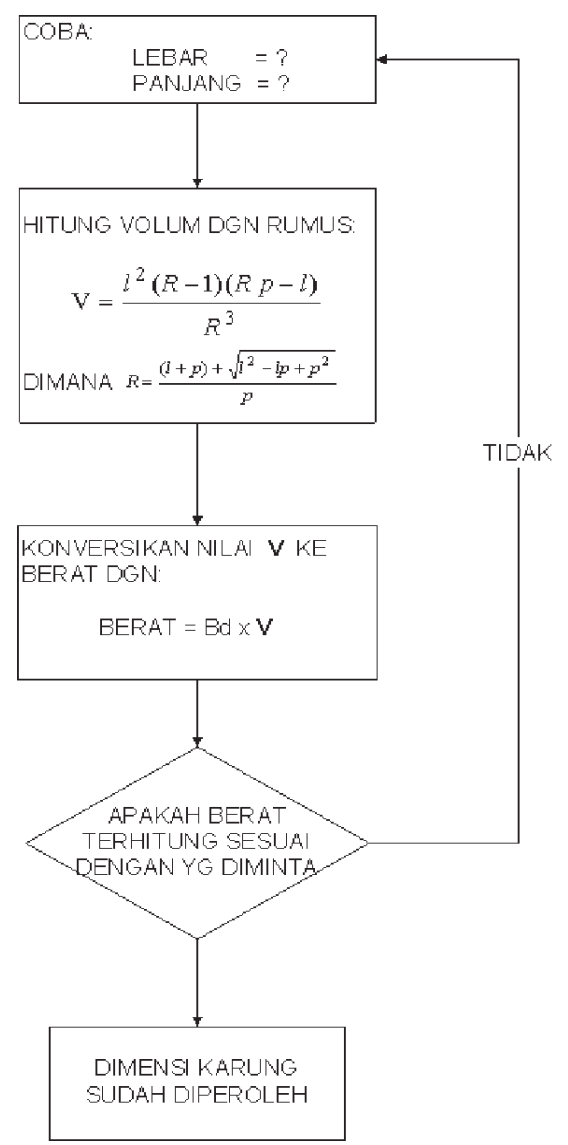

Gambar 4. Algoritma Perhitungan
Cara penggunaannya bisa digambarkan dengan diagram alir pada gambar 4 .

\section{HASIL DAN PEMBAHASAN}

Setelah V dan $\mathrm{R}$ dihitung, masih dibutuhkan bulk density bahan yang akan dikemas. Produsen karung perlu mengidentifikasi berapa $\mathrm{kg}$ berat satu liter bahan tersebut, sehingga: Bulk density, $\mathrm{Bd}=$ berat (kg) dari 1 liter bahan. Bulk density dalam kasus ini bisa dianalogkan dengan volume alat transpor material handling sebagaimana logika perhitungan Vosniakos (1989).

Dengan rumus yang diperoleh, dicoba-coba nilai $\mathbf{l}$ dan $\mathbf{p}$ sedemikian sehingga karung akan mampu memuat bahan seberat $\mathbf{m} \mathrm{kg}$. Sebagai contoh, bila diinginkan mendisain karung untuk mengemas beras kering $20 \mathrm{~kg}$ dengan $\mathrm{Bd} \approx 0,8 \mathrm{~kg} /$ liter, maka menggunakan Algoritma pada Gambar 4, diperoleh hasil perhitungan seperti terlihat pada Gambar 5, di mana karung dengan lebar $43 \mathrm{~cm}$ dan panjang $75 \mathrm{~cm}$ cukup untuk mengemas beras $20 \mathrm{~kg}$.

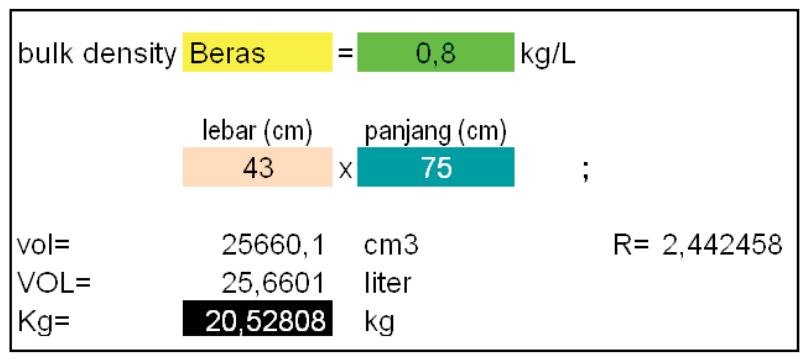

Gambar 5. Contoh Perhitungan untuk Kasus Beras

\section{SIMPULAN}

Dimensi karung (lebar dan panjang) yang sesuai sebagai pengemas suatu bahan dengan berat tertentu bisa ditentukan dengan perhitungan matematis dengan menghitung nilai volume bahan $(\boldsymbol{p} \times \boldsymbol{l})$ yang akan dikemas dan disesuaikan dengan bulk density dari bahan yang dikemas untuk menentukan berat optimal yang bisa dimuat karung tersebut. Dengan perhitungan volume $(\boldsymbol{p} \times \boldsymbol{l})$ yang dikonversikan pada ukuran berat maksimal yang bisa ditampung karung, maka desain kemasan karung yang dibuat akan mampu mengakomodasi volume maksimal tanpa merusak karung akibat beban berlebih.

\section{DAFTAR PUSTAKA}

Stewart, J. 2000. Kalkulus Universitas, Balai Pustaka, Jakarta.

Taha, H.A. 1996. Operations Research: An Introduction, sixth Edition, Prentice Hall, New York.

Tri Polyta Indonesia, Tbk. 2008. Buku Saku Plastik, Klaten. 
Vosniakos CC, Davies BJ. 1989. On the path layout and operation of an AGV system serving an FMS. The International Journal of Advanced Manufacturing Technology; 4: 24-362.
Y. Pochet and L.A. Wolsey. 1993. Lot sizing with constant batches: Formulation and valid inequalities, Mathematics of Operations Research 18, 767-785. 